\title{
PEMBERIAN INFORMASI TERHADAP PENGETAHUAN IBU HAMIL TENTANG PROGRAM PERENCANAAN PERSALINAN DAN PENCEGAHAN KOMPLIKASI
}

\author{
Devy Lestari Nurul Aulia*) \\ ${ }^{1}$ Fakultas Kedokteran, Universitas Batam \\ Email: dv.aulia87@univbatam.ac.id
}

\begin{abstract}
Batam city's AMP in 2015 was known there was 43 mothers died with mortality number 154/100.000 living birth. This number exceeding 2014 amounting to 111,5/100.000 living birth.one of the breakthrough to decrease mother mortality is delivery planning and prevention complications (P4K) with sticker. P4K action with sticker is one of the instrument or effective advice to reach MDGs target basically to decrease mother mortality which is integrated as one of desa siaga activity. The purpose of this study is to analyze the impact of providing information assistance to increase the knowledge of prenatal women about the P4K program.

The research method used in this study is pretest-posttest one group design. This study was managed from July to August 2017 at the working area of Sungai Panas Health Centre. The total population is 1,360 pregnant women, in which using the slovin formula, 93 mothers were selected to be the sample through consecutive sampling technique. The data was analyzed using T-test analysis.

At this point, the result of analysis reveals that the knowledge levels of prenatal mother on P4K before the information provision is $23.20 \pm 4.23$ and after the information provision is $30.60 \pm 0.76$ from the total score of 31 . Therefore, it is concluded that by providing the adequate information about Birth Planning and Prevention of Complication program, the prenatal women in Sungai Panas Health Centre are able to enrich their knowledge and understanding about P4K. For suggestion, it is expected that prenatal women to make planning about their childbirth and to be able to recognize the early pregnancy alarms as the prevention step
\end{abstract}

Keywords : Providing Information, Knowledge Levels, P4K

\section{ABSTRAK}

Audit Maternal Perinatal (AMP) kota Batam diketahui pada tahun 2015 terdapat 43 orang ibu meninggal dengan angka kematian sebesar 154/100.000 kelahiran hidup Angka ini melebihi keadaan tahun 2014 lalu sebesar 111,5/100.000 kelahiran hidupSalah satu upaya terobosan untuk percepatan penurunan AKI adalah Program Perencanaan Persalinan Dan Pencegahan Komplikasi (P4K) dengan stiker. Kegiatan P4K dengan stiker juga merupakan salah satu instrument atau saran yang efektif dalam mencapai sasaran MDGs terutama dalam hal penurunan AKI, yang telah terintegrasi sebagai satu kegiatan dari desa siaga. Tujuan penelitian ini adalah diketahui pengaruh pemberian informasi terhadap pengetahuan ibu hamil tentang P4K.

Design Penelitian Menggunakan quasi Eksperimen dengan metode penelitian menggunakan pretestposttest one group design diwilayah kerja Puskesmas Sungai Panas pada bulan Juli-Agustus 2017 dengan populasi sebanyak 1360 ibu hamil, penarikan sampel menggunakan rumus slovin sebanyak 93 orang dengan consecutive sampling. Analisis data menggunakan teknik analisis T-Test.

Hasil penelitian rerata pengetahuan ibu hamil sebelum diberikan informasi $23,20 \pm 4,23$ dan sesudah diberikan informasi $30,60 \pm 0,76$ dari skor 31 . Kesimpulan penelitian ini adalah Pemberian informasi tentang program perencanaan persalinan dan pencegahan komplikasi berpengaruh terhadap pengetahuan ibu hamil tentang P4K di wilayah Puskesmas Sei Panas Kota Batam. Saran bagi ibu hamil, agar melakukan perencanaan persalinan serta mengenali adanya tanda bahaya kehamilan sejak awal.

Kata Kunci : Pemberian Informasi, Pengetahuan, P4K

\section{PENDAHULUAN}

Data Angka Kematian Ibu Hamil Menurut WHO Penurunan angka kematian ibu per 100 ribu kelahiran bayi hidup masih terlalu lamban untuk mencapai target Tujuan Pembangunan Millenium (Millenium Development Goals/MDGs) dalam rangka mengurangi tiga per empat jumlah perempuan yang meninggal selama hamil dan 
melahirkan pada 2015.(Departemen Kesehatan RI, 2008) Survei Demografi Dan Kesehatan Indonesia (SDKI) tahun 2015 menunjukan Angka Kematian Ibu (AKI) mencapai 305 kematian ibu per 100.000 kelahiran hidup berdasarkan hasil Survey Penduduk Antar Sensus (SUPAS) 2015. Komitmen yang akan dicapai adalah menurunkan beberapa indikator mortalitas, seperti angka kematian ibu, angka kematian bayi dan angka kematian oleh penyakit lainnya. (Departemen Kesehatan RI, 2008)

Berdasarkan laporan sarana pelayanan kesehatan khususnya Rumah Sakit serta melalui kegiatan Audit Maternal Perinatal (AMP) kota Batam diketahui pada tahun 2015 terdapat 43 orang ibu meninggal dengan angka kematian sebesar 154/100.000 kelahiran hidup Angka ini melebihi keadaan tahun 2014 lalu sebesar 111,5/100.000 kelahiran hidup. Tingginya angka kematian ibu jumlah kematian bayi, prevelensi gizi kurang pada balita merupakan masalah besar upaya membentuk generasi yang mandiri dan berkualitas Sehingga, penting untuk melakukan penataan kembali berbagai langkah-langkah, antara lain di bidang sumber daya manusia.(DINAS KESEHATAN KOTA BATAM, 2016)

Salah satu upaya terobosan untuk percepatan penurunan AKI adalah Program Perencanaan Persalinan Dan Pencegahan Komplikasi (P4K) dengan stiker. Kegiatan P4K dengan stiker juga merupakan salah satu instrument atau saran yang efektif dalam mencapai sasaran MDGs terutama dalam hal penurunan AKI, yang telah terintegrasi sebagai satu kegiatan dari desa siaga. Isi stiker P4K yaitu nama ibu, taksiran persalinan, penolong persalinan, tempat persalinan, pendamping persalinan, transportasi dan calon donor darah.(Departemen Kesehatan RI, 2008)

Peran bidan dalam pelaksanaan Program Persalinan Dan Pencegahan Komplikasi (P4K) yaitu bidan mendata ibu hamil, bidan bersama kader atau dukun melakukan kontak denga ibu hamil suami dan keluarga untuk sepakat dalam pengisian stiker termasuk pemakian KB pasca persalinan, bidan memberikan konselinng pada ibu hamil, suami dan keluarga tentang Program Perencanaan Persalinan Dan Pencegahan Komplikasi (P4K) terutama dalam menyepakati isi dalam stiker sampai dengan alat ontrasepsi pasca persalinan yang harus tercatat dalam amanahpersalinan yang dilakukan secara bertahap yang dipegang oleh petugas tenaga kesehatan dan buku KIA yang dipegang langsung oleh ibu hamil(Departemen Kesehatan Indonesia, 2009)

Perilaku dalam penerapan P4K dipengaruhi oleh beberapa faktor, yaituFaktor yang
Mempermudah/Predisposing factors (Usia, Pendidikan, Paritas, Pendapatan Perkapita, Pengetahuan),Faktor Penguat/Reinforcing factors (Peranan Tenaga Kesehatan, Dukungan Suami, Social Budaya), Faktor Pemungkin/enabling factors (Jarak Menuju Sarana Kesehatan, Geografis)(Sukidjan Notoatmodjo, 2012)

Peran ibu hamil dalam pelaksanaan Program Perencanaan Persalinan Dan Pencegahan Komplikasi (P4K) yaitu terdatanya ibu hamil dan terpasangnya stiker P4K, adanya persalinan yang aman, adanya rencana untuk menggunakan alat kontrasepsi setelah melahirkan yang disepakati antara ibu hamil, suami, keluarga dan bidan, terlaksananya pengambilan keputusan yang cepat dan tepat bila terjadi komplikasi selama kehamilan, persalinan, dan nifas, serta meningkatkan keterlibatan tokoh masyarakat baik formal maupun non formal (Departemen Kesehatan Indonesia, 2009)

Ibu hamil dan keluarganya mempunyai rencana persalinan dan keluarga berencana yang dibuat bersama dengan penolong persalinan, keluarga mempersiapkan persalinan baik secara material, dan persiapan lingkungan (sosial, budaya), suami yang dalam masa kehamilan sampai persalinan istrinya selalu berperan aktif dalam meningkatkan kesiapan ibu hamil dalam menghadapi persalinan menguraikan dalam menghadapi persalinan suami memiliki peran serta yang besar seperti menentukan persalinan ditolong oleh bidan atau dokter menabung untuk biaya persalinan, menanyakan ke bidan, dokter kapan perkiraan tanggal persalinan, meminta penjelasan dalam inisiasi menyusui dini dan ASI Eksklusif menyiapkan kendaraan jika sewaktu - waktu ibu dan bayi perlu segera ke Rumah Sakit (Departemen Kesehatan Indonesia, 2009)

Menurut data Dinas Kesehatan kota Batam tahun 2016 didapati 64 kelurahan yang berada diwilayah kerja 17 puskesmas di kota Batam. Dikota Batam terdapat dua kelurahan/desa yang belum menerapkan program perencanaan persalinan dan pencegahan komplikasi (P4K). Dua desa tersebut berada diwilayah kerja puskesmas Sungai Panas dan puskesmas Tiban Baru. Puskesmas sungai panas berada di dua kelurahan (kelurahan bengkong indah dan sadai). Dan kelurahan yang berada di puskesmas Tiban Baru yaitu kelurahan Tiban Baru dan Tiban Lama.

Diwilayah puskesmas sungai panas terdapat 1360 jiwa ibu hamil, 642 ibu hamil berada di kelurahan Bengkong Indah dan 717 ibu hamil berada dikelurahan Sadai.(DINAS KESEHATAN KOTA BATAM, 2016) 
Penelitian terkait yang dilakukan di Desa Jepang Pakis dengan judul "Hubungan Pengetahuan Ibu Hamil Tentang Program Perencanaan Persalinan Dan Pencegahan Komplikasi Dengan Partisipasi Program" Responden Dengan Usia 20-35 Tahun (86\%), Responden Dengan Pendidikan Sma (38\%), Responden Dengan Status Bekerja (76\%), Responden Dengan Sumber Informasi Dari Tenaga Kesehatan (50 \%), Responden Dengan Pengetahuan Cukup (39,7 \%), Responden Dengan Partisipasi Program (50\%) Dan Tidak Berpartisipasi (50\%). Hasil Uji Statistik Lambda P=0.000, Dan R= 0.655. Terdapat Hubungan Yang Signifikan Antara Pengetahuan Ibu Hamil Tentang Program Pelaksanaan Perencanaan Persalinan Dan Komplikasi Dengan Partisipasi Program, Dan Mempunyai Tingkat Korelasi Yang Kuat. Arah Korelasi Positif (Fauziah, 2014)

Penelitian terkait dengan judul "Hubungan pengetahuan ibu hamil dan dukungan suami dengan kepatuhan melaksanakan program perencanaan persalinan dan pencegahan komplikasi (P4K)", yang dilihat dari hasil uji statistik menggunakan uji chi squere diperoleh nilai $P$ adalah 0,00 . Hal ini berarti bahwa ada hubungan sangat signifikan antara pengetahuan ibu hamil tentang P4K dengan kepatuhan dalam melaksanakan P4K di Wilayah Salatiga (Isyani, 2016)

Penelitian yang dilakukan di Kota Yogyakarta menujukan ibu hamil tidak siap dalam perencanaan persalinan sebanyak $80,9 \%$. tempat bersalin terbanyak $40.4 \%$ puskesmas, penolong terbanyak $74.5 \%$ bidan, pendonor darah belum merencanakan $57.4 \%$, perencanaan dana terbanyak $55.3 \%$ jaminan, transportasi terbanyak $76.6 \%$ motor, perencanaan pendamping suami $87.2 \%$, perencanaan metode KB $46.8 \%$ belum direncanakan.(Purwaningsih. Ira, 2016)

Hasil dari penelitian yang dilakukan di Kota Ambon menunjukkan bahwa implementasi P4K yaitu pemberian konseling secara komperhensif belum dilakukan oleh bidan. Kunjungan Antenatal (ANC) belum dilakukan sesuai standar. Masih ada persalinan yang ditolong dukun. Penggunaan KB pasca bersalin belum mencapai target. Tabulin dan penggalangan donor darah belum dilaksanakan. Sosialisasi program kepada masyarakat dan lintas sektor masih kurang. Jumlah bidan belum memadai. Sarana prasarana belum memadai serta tidak ada alokasi dana untuk kegiatan sosialisasi. Lemahnya manajemen control dari Dinas Kesehatan Kota Ambon dan kepala Puskesmas. Bidan belum melaksanakan forum komunikasi khusus P4K. Sikap bidan pelaksana setuju dan berkomitmen baik dalam pelaksanaan P4K. SOP pelaksanaan P4K belum tersedia. Implementasi Program Perencanaan Persalinan dan Pencegahan Komplikasi (P4K) oleh bidan di Kota ambon belum berjalan baik karena belum ada kebijakan daerah yang mengikat untuk mendukung P4K, komunikasi kepada masyarakat yang kurang, tenaga bidan, sarana dan dana yang belum memadai, lemahnya manajemen kontrol dari Dinas Kesehatan Kota Ambon serta belum adanya SOP untuk pelaksanaan P4K (Hasnawati, 2014)

Berdasarkan survei yang dilakukan dengan wawancara pada 3 ibu hamil yang melakukan pemeriksaan kehamilan di puskesmas sungai panas pada tanggal 1 April 2017. 3 dari 3 ibu hamil mengatakan tidak mengetahui Program Perencanaan persalinan dan pencegahan komplikasi (P4K), tidak menempel stiker P4K di depan rumah, dan belum mendapatkan calon pendonor darah saat persalinan nanti.Oleh karena itu peneliti tertarik untuk meneliti "Pengaruh Pemberian Informasi Terhadap Pengetahuan Ibu Hamil Tentang Program Perencanaan Persalinan Dan Pencegahan Komplikasi (P4K) di Puskesmas Sungai Panas Kota Batam Tahun 2017".

\section{METODE PENELITIAN}

Dalam membuat penelitian ini peneliti menggunakan rancangan quasi eksperiment dengan metode pretest postest one group. Pretestpostest one group design adalah penelitian ini dilakukan sebanyak dua kali yaitu sebelum eksperimen (pretest) dan sesudah eksperimen (postest) dengan satu kelompok subjek.(Soekidjo notoadmojo, 2011) Penelitian ini dilakukan di Puskesmas Sungai Panas Kota Batam Tahun 2017. Waktu penelitian ini dilakukan pada bulan JuliAgutus 2017. Populasi dalam penelitian ini adalah ibu hamil di wilayah kerja puskesmas sungai panas sebanyak 1360 ibu hamil. Sampel dalam penelitian ini adalah ibu hamil diwilayah kerja Puskesmas Sungai Panas Kota Batam sebanyak 93 ibu hamil berdasar rumus Slovin. Selanjutnya dilakukan pengolahan data Analisa Univariat dan Analisa Bivariat.

\section{HASIL DAN PEMBAHASAN}

Penelitian diatas dilakukan untuk mengetahui apakah pemberian informasi mempengarui pengetahuan ibu hami tentang Program Perencanaan Persalinan Dan Pencegahan Komplikasi (P4K) Pada Ibu Hamil Di Wilayah Kerja Puskesmas Sungai Panas Kota Batam. 
Dari Tabel 1 di dapatkan mayoritas ibu Berpendidikan SMA yaitu 49 responden (52,6\%), SMP 32 Responden (34,4\%), Sarjana 6 responden

$(6,4 \%)$, Diploma 3 responden (3,22\%), SD 3 responden $(3,22 \%)$ dan tidak sekolah 0 responden $(0 \%)$.

Tabel 1 Karekteristik Responden Berdasarkan Pendidikan ibu

\begin{tabular}{lcc}
\hline Pendidikan & $\begin{array}{c}\text { Jumlah } \\
\text { responden }\end{array}$ & $\%$ \\
\hline Tidak Sekolah & 0 & 0 \\
SD & 3 & 3,22 \\
SMP & 32 & 34,4 \\
SMA & 49 & 52,6 \\
DIPLOMA & 3 & 3,22 \\
SARJANA & 6 & 6,4 \\
\hline Jumlah & 93 & 100 \\
\hline
\end{tabular}

Tabel 2 Karakteristik Responden berdasarkan Usia Kehamilan

\begin{tabular}{ccc}
\hline Usia Kehamilan & $\begin{array}{c}\text { Jumlah } \\
\text { Responden }\end{array}$ & $\%$ \\
\hline Trimester 1 & 52 & 55,9 \\
Trimester 2 & 41 & 44,1 \\
Trimester 3 & 0 & 0 \\
\hline Total & 93 & 100 \\
\hline
\end{tabular}

Berdasarkan Tabel 2 disapatkan mayoritas responden trimester 1 yaitu 52 responden $(55,9 \%)$, dan 41 responden trimester 2 yaitu 41 responden $(44,1 \%)$

Dari table 3 Uji Normalitas data yang dilakukan peneliti metode kolmogrov-smirnov didapatkan $p>0,005$ yang berarti bahwa pengetahuan keluarga sebelum dan sesudah pemberian informasi yang di uji terdistribusi normal, dengan demikian dapat dilakukan uji T-Test.

Tabel 3 Uji Normalitas Rerata Pengetahuan Sebelum Dan Sesudah Pemberian Informasi Tentang P4K

\begin{tabular}{cccccc}
\hline Variabel & N & Rerata \pm SD & Peningkatan & Min-Max & $p$-value \\
\hline Pengetahuan Sebelum & 93 & $23,20 \pm 4,23$ & 7,4 & $13-31$ & 0,2770 \\
Pengetahuan Sesudah & 93 & $30,60 \pm 0,76$ & $7-31$ & $27-3$ \\
\hline
\end{tabular}

Tabel 4 Distribusi Frekuensi Berdasarkan Rerata Pengetahuan Sebelum Pemberian Informasi Tentang P4K Pada Ibu Hamil

\begin{tabular}{ccc}
\hline Variabel & Rerata \pm SD & Min-Max \\
\hline Pengetahuan Sebelum & $23,20 \pm 4,23$ & $13-31$ \\
\hline
\end{tabular}

Dari hasil analisis tabel 4 dijelaskan bahwa rerata pengetahuan sebelum pemberian informasi tentang P4K pada ibu hamil adalah $23,20 \pm 4,23$
Dari hasil analisis pada tabel 5 dijelaskan bahwa rerata pengetahuan sesudah pemberian informasi tentang P4K pada ibu hamil adalah $30,60 \pm 0,76$

Tabel 5 Distribusi Frekuensi Berdasarkan Pengetahuan Sesudah Pemberian Informasi Tentang P4K Pada Ibu Hamil

\begin{tabular}{ccc}
\hline Variabel & Rerata \pm SD & Min-Max \\
\hline Pengetahuan Sebelum & $30,60 \pm 0,76$ & $27-31$ \\
\hline
\end{tabular}

Tabel 6 Distribusi Frekuensi Perbedaan Rerata Pengetahuan Ibu Hamil Sebelum dan Sesudah Pemberian Informasi Tentang P4K

\begin{tabular}{cccccc}
\hline Variabel & N & Rerata \pm SD & Peningkatan & SD & $p$-value \\
\hline Pengetahuan Sebelum & 93 & $23,20 \pm 4,23$ & \multirow{2}{*}{7,4} & 4,23 & 0,2770 \\
Pengetahuan Sesudah & 93 & $30,60 \pm 0,76$ & & 0,76 & \\
\hline
\end{tabular}

Dari hasil penelitian menjelaskan bahwa rerata pengetahuan ibu hamil tentang P4K sebelum pemberian informasi 23,20 dan sesudah pemberian informasi 30,60, sehingga mengalami peningkatan 
sebesar 7.4. Hasil analisis lebih lanjut didapatkan nilai $p 0.000(p<0.05)$ yang berarti bahwa pada perbedaan yang signifikan skor rerata pengetahuan sebelum dan sesudah pemberian informasi.

\section{Pengetahuan Ibu Hamil Sebelum diberikan Informasi}

Berdasarkan hasil penelitian yang telah dilakukan pada 93 responden diketahui nilai rerata pengetahuan ibu hamil sebelum diberikan informasi $23,20 \pm 4,23$ dari skor total 31 . Dari hasil yang didapatkan menunjukan bahwa pentingnya pemberian informasi pada responden untuk meningkatkan pengetahuan.

Berdasarkan hasil penelitian didapatkan bahwa mayoritas ibu hamil masih belum mengerti tentang P4K terutama mengenai isi stiker P4K yang tertuang pada soal No 4. Mayoritas ibu hamil juga tidak mengetahui pelayanan antenatal sesuai standar yang tertuang pada kuesioner pada No 7 . Responden dalam penelitian ini mayoritas belum mengerti tentang donor darah yang dapat dilihat dari kuesioner No 17 dan No 18 yang mayoritas ibu menjawab salah. Menurut 93 responden dalam penelitian ini menyatakan ambulan desa diperoleh berdasarkan keinginan ibu hamil dilihat dari kuesioner No 23 tentang ambulan desa, dan pada kuesioner No 26 tentang KB pasca bersalin mayoritas ibu menjawab salah .

Responden yang belum memahami tentang P4K disebabkan kurangnya informasi tentang P4K karena dengan informasi yang cukup maka pengetahuan seseorang akan menjadi lebih baik. Pengetahuan seseorang dapat dipengaruhi oleh beberapa faktor, salah satunya adalah informasi. Pengetahuan seseorang biasanya diperoleh dari berbagai macam sumber misalnya media massa, media elektronik, buku-buku, petugas kesehatan, media poster, kerabat dekat dan sebagainya.(Soekidjo Notoatmodjo, 2010)

Ada tidaknya informasi tentang kesehatan berpengaruh terhadap perubahan perilaku seseorang.(Sukidjan Notoatmodjo, 2012) Jika seseorang terpapar secara terus-menerus dengan informasi maka kemungkinan orang tersebut akan paham secara benar informasi tersebut. Berdasarkan keterpapan informasi yang didapat sebagian responden tidak terpapar terhadap informasi tentang Program Perencanaan Persalinan dan Pencegahan Komplikasi (P4K) dalam stiker P4K. Sumber informasi tentang P4K sebagian besar didapatkan dari bidan. Disini dapat dilihat bahwa media untuk mendapatkan informasi kesehatan khususnya tentang P4K masih kurang. Informasi dari televisi hanya muncul kadang-kadang saja, begitu juga untuk media cetak jarang yang menampilkan tentang program ini.

Selain pengetahuan dalam diri dan keterpaparan informasi, minat juga merupakan salah satu faktor yang mempengauhi pengetahuan seseorang. Minat sebagai suatu kecenderungan atau keinginan yang tinggi terhadap sesuatu. Minat menjadikan seseorang untuk mencoba dan menekuni suatu hal, sehingga seseorang memperoleh pengetahuan yang lebih mendalam. Mayoritas responden mengatakan tidak pernah mencari tahu informasi tentang Program Perencanaan Persalinan dan Pecegahan Komplikasi (P4K) dalam stiker yang diberikan tenaga kesehatan atau bidan didalam buku pemeriksaan. Salah satu pelaksanaan program ini adalah dengan menempelkan stiker. Jadi diwajibkan bagi semua ibu hamil agar rumahnya tertemper stiker. Namun pada penelitian ini didapatkan bahwa penempelan stiker dilakukan oleh ibu hamil sendiri, padahal seharusnya penempelan stiker dilakukan oleh bidan sehingga bidan juga dapat memberikan pendidikan kesehatan dan informasi mengenai isi komponen stiker P4K.

Pengetahuan ibu hamil sebelum diberi penyuluhan sebagian besar adalah kurang sebanyak 37 responden (52,1\%). Pengetahuan yang kurang pada responden menunjukkan bahwa pentingnya pemberian penyuluhan pada responden untuk meningkatkan pengetahuan. Berdasarkan penyuluhan yang disampaikan, setiap responden memiliki daya tanggap yang berbeda dalam menangkap informasi yang diterima, hal ini dikarenakan faktor minat, pendidikan, keterpaparan informasi.(Wahyuni, 2013)

Berdasarkan uraian diatas disimpulkan bahwa perlu adanya pemberian informasi tentang Program Perencanaan Persalinan dan Pencegahan Komplikasi (P4K) agar responden dapat lebih memahami tentang Program Perencanaan Persalinan dan Pencegahan Komplikasi (P4K) dari yang sebelumnya.

\section{Pengetahuan lbu Hamil Sesudah Diberikan Informasi}

Berdasarkan hasil penelitian yang telah dilakukan pada 93 ibu hamil sesudah diberikan informasi tentang Program Perencanaan Persalinan dan Pencegahan Komplikasi (P4K) adalah 30,60 dari skor 31. Hal ini menunjukkan bahwa sebagian besar ibu hamil di wilayah kerja puskesmas Sungai Panas mengalami Peningkatan dari yang sebelumnya yaitu 7,4 . 
Peningkatan pengetahuan yang terjadi dalam hal ini dikarenakan pemberian informasi yang diberikan melalui pemberian brosur dan konseling mengenai P4K. Faktor-faktor yang mempengaruhi pengetahuan diantaranya pendidikan, umur, pengalaman, lingkungan, dan informasi/media massa.(Soekidjo Notoatmodjo, 2012) Hasil ini membuktikan pentingnya penyuluhan pada setiap kegiatan untuk meningkatkan pengetahuan ibu. Penyuluhan adalah suatu kegiatan pendidikan yang bersifat non formal yang ditujukan untuk mengubah perilaku manusia, diantaranya pengetahuan, sikap dan keterampilan.(Vidy, 2016) Pengetahuan adalah hasil dari tahu dan ini terjadi setelah terjadi pengindraan terhadap suatu objek tertentu. Pengindraan terjadi melalui panca indera manusia, yakni indera pendengaran, penglihatan, penciuman, rasa dan raba, sebagian besar pengetahuan manusia diperoleh melalui mata dan telinga. Sebagaimana informasi yang diberikan oleh peneliti berupa brosur dan konseling yang dapat diserap melalu penginderaan yaitu penglihatan dan pendengaran.

Peningkatan pengetahuan yang terjadi dalam hal ini dikarenakan mayoritas responden berpendidikan menengah yang menjadi faktor pendukung dalam menyerap informasi yang diberikan. Pendidikan adalah bimbingan yang diberikan kepada orang lain agar dapat memahami sesuatu hal. Tidak dapat dipungkiri bahwa semakin tinggi pendidikan seseorang, semakin mudah pula mereka menerima informasi dan pada akhirnya pengetahuan yang dimilikinya akan semakin banyak.(Mubarak, Wahit lqbal, 2011)

Pengetahuan ibu hamil tentang P4K. Hasil peneliti sebelum diberi penyuluhan sebagian besar adalah kurang sebanyak 37 responden (52,1\%), ibu hamil berpengetahuan cukup sebanyak 28 responden $(39,4 \%)$ dan ibu hamil yang berpengetahuan baik sebanyak 6 responden $(8,5 \%)$ sedangkan setelah diberi penyuluhan, pengetahuan ibu hamil dalam kategori baik meningkat menjadi 8 responden $(11,3 \%)$, ibu hamil berpengetahuan cukup meningkat menjadi 38 responden $(53,5 \%)$ sedangkan ibu hamil yang berpengetahuan kurang mengalami penurunan menjadi 25 responden $(35,2 \%)$.(Wahyuni, 2013)

Sebagian besar responden telah menempuh pendidikan hingga tingkat SMA/SMK sebanyak 37 orang $(52,1 \%)$ maka terjadi peningkatan pengetahuan setelah diberikan informasi. Pendidikan dapat mempengaruhi cara pandang seseorang terhadap informasi baru yang diterimanya.(Wahyuni, 2013) Maka dapat dikatakan bahwa semakin tinggi tingkat pendidikannya, semakin mudah seseorang menerima informasi yang didapatnya. Pada penelitian ini dibuktikan dengan pendidikan yang tinggi maka semakin mudah menerima informasi saat penyuluhan dan semakin meningkatkan pengetahuan tentang P4K.

Dari uraian tersebut dapat disimpulkan bahwa informasi yang diterima melalui konseling dan brosur meningkatkan pengetahuan ibu tentang Program Perencanaan dan Pencegahan Komplikasi (P4K) diwilayah Kerja Puskesmas Sei Panas Kota Batam tahun 2017.

\section{Pengaruh Pemberian Infomasi Terhadap Pengetahuan lbu Hamil Tentang Program Perencaan Persalinan dan Pencegahan Komplikasi}

Berdasarkan hasil penelitian yang telah dilakukan pada 93 responden diketahui pengetahuan ibu hamil sebelum diberikan informasi dan sesudah diberikan informasi dilihat dari hasil mean sebelum diberikan informasi dan sesudah diberikan informasi terjadi peningkatan, sebelum diberikan informasi nilai rerata 23,20 dan sesudah diberikan informasi nilai rerata menjadi 30,60 . Hal ini terdapat peningkatan 7,4 sesudah diberikannya informasi. Dari hasil uji bivariat dengan menggunakan $T$-Test didapatkan nilai $p$-value 0,000 $(p<0,05)$ dengan demikian $\mathrm{Ho}$ ditolak dan $\mathrm{Ha}$ diterima. Dan selanjutnya dapat disimpulkan ada pengaruh pemberian informasi terhadap pengetahuan ibu hamil mengenai Program Perencaan dan Pencegahan Komplikasi di Wilayah Kerja Puskesmas Sei Panas Kota Batam.

Pengetahuan seseorang dipengaruhi oleh beberapa faktor yang salah satunya adalah paparan informasi dan status pendidikan yang didapatkan oleh seseorang melalui media cetak ataupun tenaga kesehatan seperti pelatihan, penyuluhan dan konseling.(Soekidjo Notoatmodjo, 2012) Berdasarkan proses pemberian informasi peneliti memberikan konseling dengan metode perorangan yang menggunakan alat bantu yaitu brosur kepada responden. Brosur yang diberikan berisi tentang materi yang terkait dengan P4K.

Brosur digunakan untuk memberikan keterangan singkat tentang suatu masalah. Leaflet atau brosur dapat diberikan atau disebarkan pada saat pertemuan-pertemuan dilakukan seperti pertemuan FGD, pertemuan Posyandu, kunjungan rumah, dan lain-lain. Konseling yang peneliti lakukan melalui Pendekatan perorangan dengan metode "Kombinasi". Dalam hal ini termasuk demonstrasi cara (dilihat, didengar, dan lain-lain). Adapun respon dari responden yang memiliki antusias saat konseling berlangsung, dengan 
memberikan pertanyaan pada peneliti terkait P4K, Persiapan Persalinan, macam-macam komplikasi pada kehamilan maupun saat bersalin, sehingga responden menjadi lebih memahami apa saja yang tidak dimengerti tentang P4K.

Pengaruh penyuluhan tentang Program Perencanaan Persalinan dan Pencegahan Komplikasi (P4K) Terhadap Upaya Pencegahan Komplikasi Pada Ibu Hamil didesa Ngestihardjo Kasihan Baitul yang menunjukan adanya peningkatan.(Andira, 2015) Dimana didapati sikap dengan kategori baik sebelum diberikan penyuluhan 10 orang $(33,3 \%)$, setelah diberikan penyuluhan 20 orang $(66,7 \%)$, sikap dengan kategori cukup sebelum diberikan penyuluhan 18 orang $(60 \%)$ setelah diberi penyuluhan 10 orang (33,3\%), sikap dengan kategori kurang sebelum diberi penyuluhan 2 orang $(6,7 \%)$ setelah diberi penyuluhan tidak ada respondeng dengan kategori kurang $(0)$, dengan nilai $p=0,000(p<0,005)$.

Penelitian ini sejalan dengan penelitian yang berjudul Pengaruh Penyuluhan Terhadap Perencanaan Persalinan Dan Pencegahan Komplikasi Pada Ibu Hamil Berisiko Di Puskesmas Pundong Bantul Tahun 2015.(Ulfa, 2015) Dimana didapati hasil penelitian menunjukkan rerata perencanaan persalinan dan pencegahan komplikasi sebelum dilakukan penyuluhan (pre test) sebesar 5,23 . Rerata perencanaan persalinan dan pencegahan komplikasi setelah dilakukan penyuluhan (post test) meningkat menjadi 6,13.

Hasil penelitian yang menunjukkan bahwa ada hubungan yang bermakna antara pemberian penyuluhan $\mathrm{P} 4 \mathrm{~K}$ dengan perencanaan persalinan dan pencegahan komplikasi. (Ulfa, 2015)

Penelitian ini sama-sama terdapat pengaruh pemberian informasi berupa konseling atau penyuluhan tentang Program Perencanaan Persalinan dan Pencegahan Komplikasi (P4K) dimana sama-sama menambah informasi bagi responden, sehingga pengetahuan menjadi meningkat.

\section{SIMPULAN}

Berdasarkan penelitian yang dilakukan di Wilayah Kerja Puskesmas Sungai Panas Tentang Program Perencanaan Persalinan dan Pencegahan Komplikasi Pada Ibu Hamil sebanyak 93 responden. Hasil yang didapatkan dari penelitian ini adalah Ada perbedaan signifikan skor rerata pengetahuan ibu hamil tentang Program Perencanaan Persalinan dan Pencegahan Komplikasi (P4K) sebelum dan sesudah diberlikan informasi sehingga mengalami peningkatan sebesar 7,4 .

\section{SARAN}

Saran bagi ibu hamil, agar melakukan perencanaan persalinan serta mengenali adanya tanda bahaya kehamilan sejak awal.

\section{DAFTAR PUSTAKA}

Andira, Y. (2015). Pengaruh Penyuluhan Tentang P4K Terhadap Upaya Pencegahan Komplikasi Pada Ibu Hamil Di Desa Ngestihardjo Kasihan Bantul.

Departemen Kesehatan Indonesia. (2009). Pedoman Program Perencanaan Persalinan Dan Pencegahan Komplikasi (P4k) dengan stiker. JAKARTA.

Departemen Kesehatan RI. (2008). Pusat Promosi Kesehatan, Pedoman Pengelolaan Promosi Kesehatan, Dalam Pencapaian PHBS. JAKARTA.

DINAS KESEHATAN KOTA BATAM. (2016). Profil Kesehatan Kota Batam.

Fauziah, R. (2014). Hubungan Pengetahuan Ibu Hamil Tentang Program Perencanaan Persalinan Dan Pencegahan Komplikasi Dengan Partisipasi Program.

Hasnawati, dkk. (2014). Implementasi Program Perencanaan Persalinan dan Pencegahan Komplikasi (P4K) oleh Bidan pada Puskesmas di Kota Ambon (Studi pada Puskesmas Binaan).

Isyani, R. (2016). Hubungan Pengetahuan Ibu Hamil dan Dukungan Suami dengan Kepatuhan Melaksanakan Program Perencanaan Persalinan dan Pencegahan Komplikasi (P4K) di Kota Salatiga. universitas sebesla maret.

Mubarak, Wahit lqbal, dkk. (2011). Promosi Kesehatan untuk Kebidanan. JAKARTA: Salemba Medika.

Notoatmodjo, S. (2010). Promosi Kesehatan Teori dan Aplikasi (Edisi Revisi). JAKARTA: Rineka Cipta.

Notoatmodjo, S. (2012). Pendidikan Promosi dan Perilaku Kesehatan. Jakarta: Rineka Cipta.

Notoatmodjo, S. (2012). Pendidikan Promosi dan Perilaku Kesehatan. JAKARTA: Rineka Cipta.

Purwaningsih. Ira. (2016). Gambaran Program Perencanaan Persalinan Dan Pencegahan Komplikasi (P4k) Pada Ibu Hamil Trimester lii Di Puskesmas Jetis I. Stikes Jenderal Achmad Yani.

Soekidjo notoadmojo. (2011). Metode Penelitian Kesehatan. JAKARTA: Rineka Cipta.

Ulfa, G. (2015). Pengaruh Penyuluhan Terhadap Perencanaan Persalinan Dan Pencegahan 
Komplikasi Pada Ibu Hamil Berisiko di Puskesmas Pundong Bantul.

Vidy. (2016). pengertian media komunikasi. Retrieved from http://artikelaz.com/pengertian-media-komunikasi/

Wahyuni, W. (2013). Efektivitas Penyuluhan
Kesehatan Tentang Program Perencanaan Persalinan Dan Pencegahan Komplikasi Terhadap Peningkatan Pengetahuan P4K Pada Ibu Hamil di Wilayah Puskesmas Karangnongko. 